ORIGINAL ARTICLE

\title{
Congenital Cardiovascular Anomalies among Cases of Down Syndrome: A Hospital Based Review of Cases in TikurAnbessa Specialized Hospital, Ethiopia
}

\author{
Ahmed Muntha ${ }^{1}$, Tamirat Moges ${ }^{2 *}$
}

\begin{abstract}
OPEN ACCESS
Citation: Ahmed Muntha, Tamirat Moges. Congenital Cardiovascular Anomalies among Cases of Down Syndrome: A Hospital Based Review of Cases in TikurAnbessa Specialized Hospital, Ethiopia. Ethiop J Health Sci. 2019;29(2):165.

doi:http://dx.doi.org/10.4314/ ejhs.v29i2.3 Received: February 05, 2018

Accepted: October 24, 2019

Published: March 1, 2019

Copyright: () 2019 Ahmed M., et al. This is an open access article distributed under the terms of the Creative Commons Attribution License, which permits unrestricted use, distribution, and reproduction in any medium, provided the original author and source are credited. Funding: Nil

Competing Interests: The authors declare that this manuscript was approved by all authors in its form and that no competing interest exists.

Affiliation and Correspondence:

${ }^{1}$ Ras Desta Hospital, Addis Ababa, Ethiopia

${ }^{2}$ Department of Pediatrics and Child Health, College of Health Sciences, Addis Ababa University, Ethiopia

*Email:mogest98@yahoo.com
\end{abstract}

\section{ABSTRACT}

BACKGROUND: In developing countries, infants with Down syndrome and cardiac defect are at increased risk of dying. Congenital heart diseases occur in 40-50\% of affected infants. Endocardial cushion defect accounts for the most. Pattern of cardiac defects in Down syndrome vary with ethnicity. The current study aims to determine pattern of cardiac defects and survival of patients in our institution.

METHODS: Hospital based review of cases, between April 2010 and may 2015 were made. Data were analyzed using SPSS version 20 software quantitatively with plotted Kaplan Meier survival curve done. RESULTS: Down syndrome cases, 53 male and 63 females with cardiac anomalies, were described. Patent ductus arteriosus occurs in 57(36.5\%), Ventricular septal defect in 31(19.9\%), Atrial septal defect in 30(19\%), Atrio-ventricular septal defect in 29(18.6\%),Tetralogy of Fallot in 4(2.6\%) and others in 5(3.2\%) cases. Cases were alive, lost to follow-up and died in 59, 35 and 22 cases, respectively. The overall death rate was $19 \%$ and two-third of them died during infancy with females dying at an earlier age than males. Pulmonary hypertension, hypothyroidism and gastrointestinal disorders were diagnosed in 46, 21 and 4 of the cases, respectively. Reasons for lost to follow-up were discussed.

CONCLUSION: The pattern of cardiac anomalies in our study among Down syndrome cases is dominated by Patent ductus arteriosus while, the overall survival of cases is guarded as majority of deaths occurred during infancy

KEYWORDS: Down syndrome, cardiovascular anomaly, congenital heart disease, trisomy 21.

\section{INTRODUCTION}

Down syndrome (trisomy 21) is the most common chromosomal abnormality occurring with estimated incidence of 1.1 per 1,000 live births (1). The incidence of Down syndrome (DS) is increasing over the past few decades $(2,3)$.Coupled with the increase in the incidence, 
there has been a substantial increase in the life expectancy of cases with congenital cardiac defects in developed countries (4). As a matter of fact, following cardiac surgery, DS does not confer a significant mortality risk for most operations performed, even though post-operative morbidity remains common (5).

On the other hand, in developing countries, infants with DS having cardiac defect are at increased risk of dying in the first year of life (6). Although such infants require similar management as non-DS babies, access to treatment is a major challenge (2). Thus, congenital heart disease (CHD) is the major determinant of early mortality in these group of patients (7).

In developed countries, survival to 1 year is now greater than $91 \%$ whereas $85 \%$ of cases can survive until the age of 10 years (8-10). Furthermore, survival studies in these countries showed that year of birth, gestational age at delivery, standardized birth weight, karyotype, and presence of additional structural anomalies were significant predictors of survival (2).

Reports have indicated that the distribution of CHD in children with DS may vary with ethnicity (11). As an illustration, the most common CHD associated with DS in the western literature is Atrio-ventricular septal defect followed by VSD, ASD, PDA and TOF (12). On the other hand, in a report from Koria, ASD was the most common defect followed by VSD, PDA, and AVSD in decreasing order (13). Then again, VSD was the commonest defect, followed by PDA, AVSD, and TOF in a report from Pakistan. Uniquely, the most common single defect reported in the Guatemalan study was PDA. This was also the most frequent concomitant cardiac anomaly coexisting with other congenital cardiac lesions (14).

Two reports were made on the pattern of CHD in DS from Africa. One report from Sudan showed that Common AV canal defect was the commonest lesion followed by VSD and TOF (15). This pattern was similar to the one in the developed world. The other African study which was from Libya showed that the most common isolated cardiac lesion reported was ASD, followed by AVSD and VSD in descending order (16).
Diagnosis of DS depends on the finding of positive karyotype for trisomy (21). However, in places where karyotyping is not routinely done, the diagnosis is made based on phenotypic features. Correlation of phenotypic features and karyotyping has been studied. As a result, accuracy of clinical suspicion ranges between $64 \%$ and $86 \%$ that of karyotyping. It was also suggested that the accuracy of clinical diagnosis increases when the assessment is made by a neonatologist or senior Pediatrician (17). Moreover, it was suggested to use a diagnostic index like Fried's index, which may be useful in improving the accuracy of clinical diagnosis of DS (18)

There is scarce data on the pattern and survival of children with DS having CHD in Ethiopia. An extrapolated data by "right diagnosis" estimated the number of cases of DS in Ethiopia as 89,170 per $71,336,571$ population $(15,16)$. Similarly, a multi-center hospital based study showed that the prevalence of DS among babies with birth defects is estimated to be $2 \%$ (19). Although in there is an assumption that cases may die at an early age in Ethiopia for lack of early diagnosis and intervention, there is no enough evidence supporting this assumption.

The current study aims to look into these pattern of congenital cardiac anomalies and the factors affecting survival of cases. This will be the first report concerning Down syndrome in children from our institution.

\section{MATERIALS AND METHODS}

Study site: The study was conducted at Tikur Anbessa Specialized Hospital (TASH) which is located in the center of the capital, Addis Ababa. It is the major tertiary and university hospital in the country. The pediatric cardiac clinic is one of the units in the Department of Pediatrics, hence run by pediatric cardiologists, fellows and pediatric residents. The Congenital Cardiac Clinic runs five days per week and is equipped with electrocardiography and echocardiographic machines used by pediatric cardiologists and fellows. Cases of DS with cardiac anomaly are followed both at the pediatric cardiac and endocrine clinics. In the endocrine clinic cases are screened for hypothyroidism. The clinic mainly

DOI: http://dx.doi.org/10.4314/ejhs.v29i2.3 
deals with the endocrine problems of DS cases; otherwise, cases are referred to other necessary specialties such as Eye/ENT or neurologic care specialists from this clinic when it is indicated.

Study design and period: Retrospective chart review of cases was conducted using patient registry between April 2010 and May 2015. The inclusion criteria includes cases fulfilling the definition of both phenotypes Down syndrome and congenital cardiac anomaly. The exclusion criteria applied in cases with no echocardiographic confirmation of heart disease, cases with patent foramen ovale, and incomplete chart.

Sample size was calculated using Single population proportion formula $(\mathrm{Z} 2 *(\mathrm{p}) *(1-\mathrm{p}) /(\mathrm{e}) 2)$ formula, where $\mathrm{z}=1.28$ ( for $80 \%$ confidence level), $\mathrm{P}=$ prevalence of $\mathrm{CHD}$ in $\mathrm{DS}$ as $45 \%$, $\mathrm{e}($ margin of error $)=0.05$, giving a sample size of 162 cases (20).

Study variables: Patient's current age, sex, parental address (including telephone number) reason for referral, referring institution, age at first diagnosis, history of consanguinity, maternal age at conception, ethnicity, parent/gardian religion, family history of congenital heart disease, types of cardiac lesion, pulmonary hypertension, current patient status (alive, died or lost to follow-up), age at death, or lost to follow-up were inquired.

Data collection procedure: Data were collected from patients' chart manually on to a structured questionnaire format. Log books from the clinic were used to get patients card number and identification details. Additional information was gathered from parents/gardians by telephone in cases of lost to follow-up. Death was confirmed from the hospital record and/or from parents/gardians report during telephone enquiry.

Data analysis: Data coding and manual proofreading were done before entering the data onto a computer program. Data were entered into SPSS software version 20. Categorical data were analyzed by proportions and percentiles. Continuous data were analyzed using mean, median and standard deviation. Kaplan meier survival curve was plotted to see the survival pattern. The Log Rank chi-square test was used to compare survival events whenever necessary. Statistical significance was considered with $\mathrm{P}$ value $<0.05$.
Operational definitions: 'Congenital cardiovascular anomalies' refer to anatomic malformation of the heart or great vessels as confirmed by echocardiography, occurring during intrauterine development, irrespective of the age at presentation (21). 'Current status alive' means that the patient appeared on the last date of follow-up. On the other hand, 'current status unknown' means that the patient did not appear on the last two or more days of follow-up. The patient is lost from follo-up, or may have a lesion which spontaneously closed, or he/she may have died. On the other hand, 'died' refers to death naccepted true when it is confirmed from hospital record or when parents/guardians confirmed death during telephone enquiry.

'Phenotypic Down syndrome' means physical appearance and behavior of patients with Down syndrome that includes, low muscle tone (babies appear "floppy"), flat facial features, small nose, upward slanting of the eyes, epicantal fold, small abnormally shaped ears, simian crease, hyper flexibility (excessive ability to extend joints), one flexion furrow instead of two on the fifth finger, extra space between the big toe and the second toe, evidence of congenital heart disease, and hypothyroidism. The phenotypic diagnosis of DS is made where there are 8 or more of the above Down's features $(17,22)$.

'Pulmonary hypertension ( $\mathrm{PH})$ ' is defined as pulmonary arterial pressure above $25 \mathrm{mmHg}$ at rest on echocardiographic evaluation. The degree of PH was classified as mild (PAP between 25 and $40 \mathrm{mmHg}$ ), moderate (PAP between 41 and $55 \mathrm{mmHg}$ ) or severe (PAP greater than $55 \mathrm{mmHg}$ ), based on the echocardiographic findings. The analysis of the regurgitation jet of the tricuspid valve was used to determine the degree of $\mathrm{PH}$. The diagnosis of $\mathrm{PH}$ was established by estimating the peak systolic gradient of the shunt between the ventricles through the Bernoulli equation in patients with intracardiac defects (Ventricular septal defect). In cases with patent ductusarteriosus (PDA), we used the shunt between the aorta and the pulmonary artery (23).

\section{RESULTS}

We retrieved 119 phenotypic DS cases with congenital cardiac anomalies, of which 116

DOI: http://dx.doi.org/10.4314/ejhs.v29i2.3 
fulfilled the inclusion criteria and were described. Male-to-female ratio is $1: 1.15$. Mean and median ages at presentation were 18.6 and 9 months (IQR 13 months), respectively. Seventy-seven (66.4\%) cases were younger than 12 months.

Table 1 shows the socio-demographic characteristics of the cases. Table 2 displays the pattern of congenital heart disease. Acyanotic congenital heart diseases accounted for 109 cases. The most frequent cardiac lesions in descending order were PDA, VSD, ASD, and AVSD. Multiple congenital heart diseases were seen in 39 cases. The most frequent concomitant malformation co-existing with other congenital cardiac lesions was PDA. PDA, and AVSD were observed more frequently in females while VSD was commonly seen in males.

We contacted 59 cases till the end of the study.Thirty-five cases were lost to follow-up while 22 cases died. The reasons for lost to follow-up were death of family members in 1 case, apparently improved condition in 2 cases, economic reasons in 2 cases, and tendency for another option (holy water) in 3 cases, respectively. In 19 cases, telephone number was not recorded on the chart; therefore, it was not possible to contact families. In 5 cases, the registered telephone number was not working. Mean and median ages at death were 21 and 18 months, respectively.

Table 1: Socio-demographic profile of cases of congenital cardiovascular anomalies in cases of
Down syndrome, TASH 2018

\begin{tabular}{|c|c|c|}
\hline & $\begin{array}{l}\text { Number of } \\
\text { patients }\end{array}$ & Percent $9(\%)$ \\
\hline \multicolumn{3}{|l|}{ Age category } \\
\hline $0-11$ months & 71 & 61 \\
\hline 12-59 months- & 34 & 29 \\
\hline $60-144$ months- & 10 & 8.6 \\
\hline Total & 116 & 100 \\
\hline \multicolumn{3}{|l|}{ Sex of the patient } \\
\hline Male & 53 & 46 \\
\hline Female & 63 & 54 \\
\hline Total & 116 & 100 \\
\hline \multicolumn{3}{|l|}{ Religion } \\
\hline Orthodox Christian & 65 & 56 \\
\hline Protestant Christian & 27 & 23 \\
\hline Muslim & 23 & 20 \\
\hline Missing information & 1 & 0.9 \\
\hline Total & 116 & 100 \\
\hline \multicolumn{3}{|l|}{$\begin{array}{l}\text { Maternal age at } \\
\text { conception(yr) }\end{array}$} \\
\hline $21-35$ & 40 & 69 \\
\hline $36-43$ & 18 & 31 \\
\hline Missing information & 58 & 50 \\
\hline Total & 116 & 100 \\
\hline \multicolumn{3}{|l|}{ Referring institution } \\
\hline Government & 50 & 43 \\
\hline Private & 30 & 26 \\
\hline Other & 10 & 8 \\
\hline Missing information & 26 & 22 \\
\hline Total & 116 & 100 \\
\hline
\end{tabular}

Table 2: Pattern of congenital heart disease among children born with DS, TASH 2017.

\begin{tabular}{lll}
\hline Type of CHD & Number & Percentage \\
\hline Patent ductusarteriosus(single and combined) & 57 & $36.5 \%$ \\
Ventricular septal defect & 31 & $19.9 \%$ \\
Atrial septal defect & 30 & $19.0 \%$ \\
Atrio-ventricular septal defect & 29 & $18.6 \%$ \\
Tetralogy of fallot & 4 & $2.6 \%$ \\
Co-arctation of Aorta & 3 & $1.9 \%$ \\
Pulmonary stenosis & 1 & $0.6 \%$ \\
Mitral valve prolapse & 1 & $0.6 \%$ \\
Total & $156^{*}$ & $100 \%$ \\
\hline
\end{tabular}

* One patient may have more than one Cardiac lesions

DOI: http://dx.doi.org/10.4314/ejhs.v29i2.3 
The survival pattern of cases is shown in Figures 1 and 2 by Kaplan Meier survival curve. Most deaths were observed during the first 48 months (Figure
1). Females died earlier than males as seen in the lower survival curve (Figure 2).

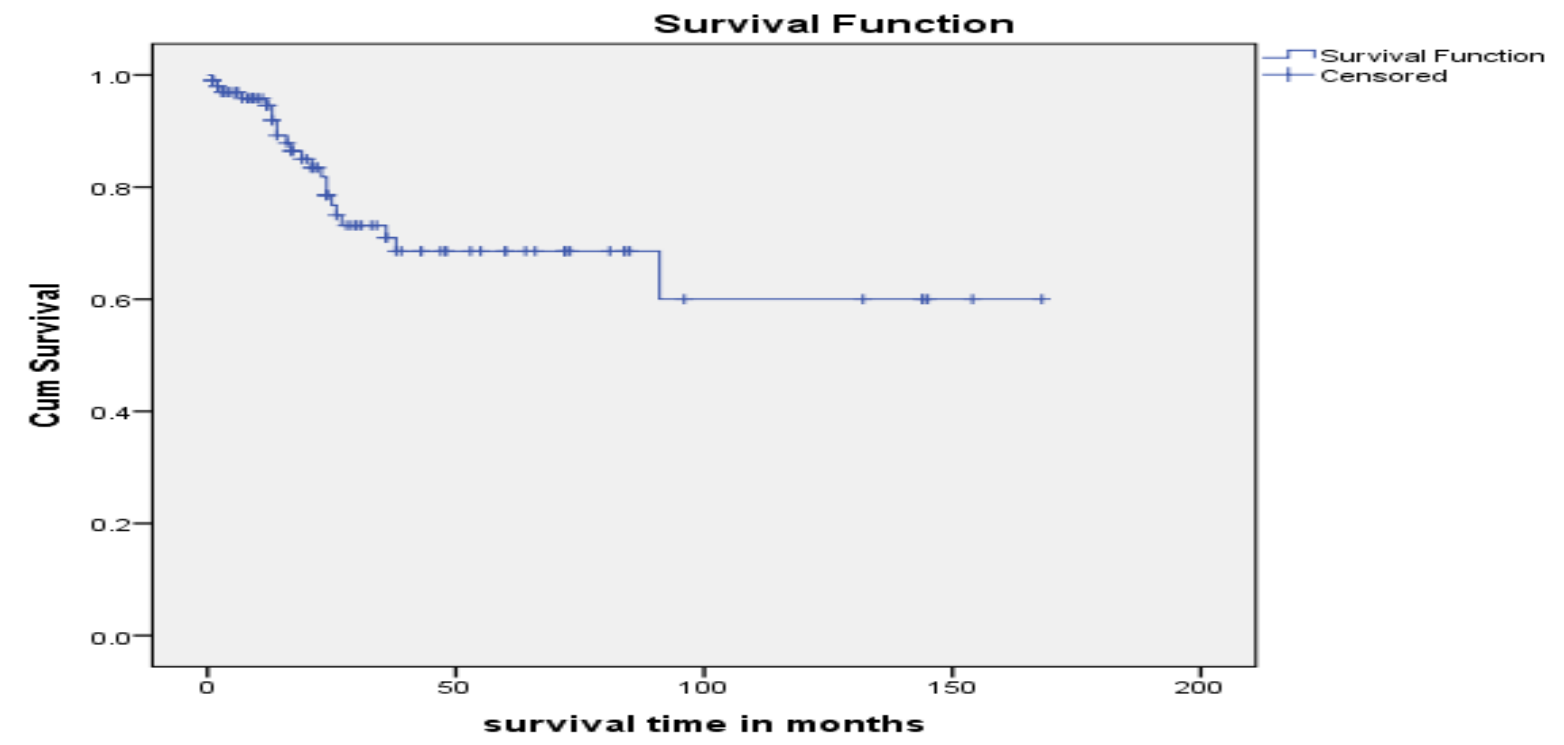

Figure 1: Kaplan meier survival curve among Down syndrome cases born with congenital cardiovascular anomalies, TASH 2017.

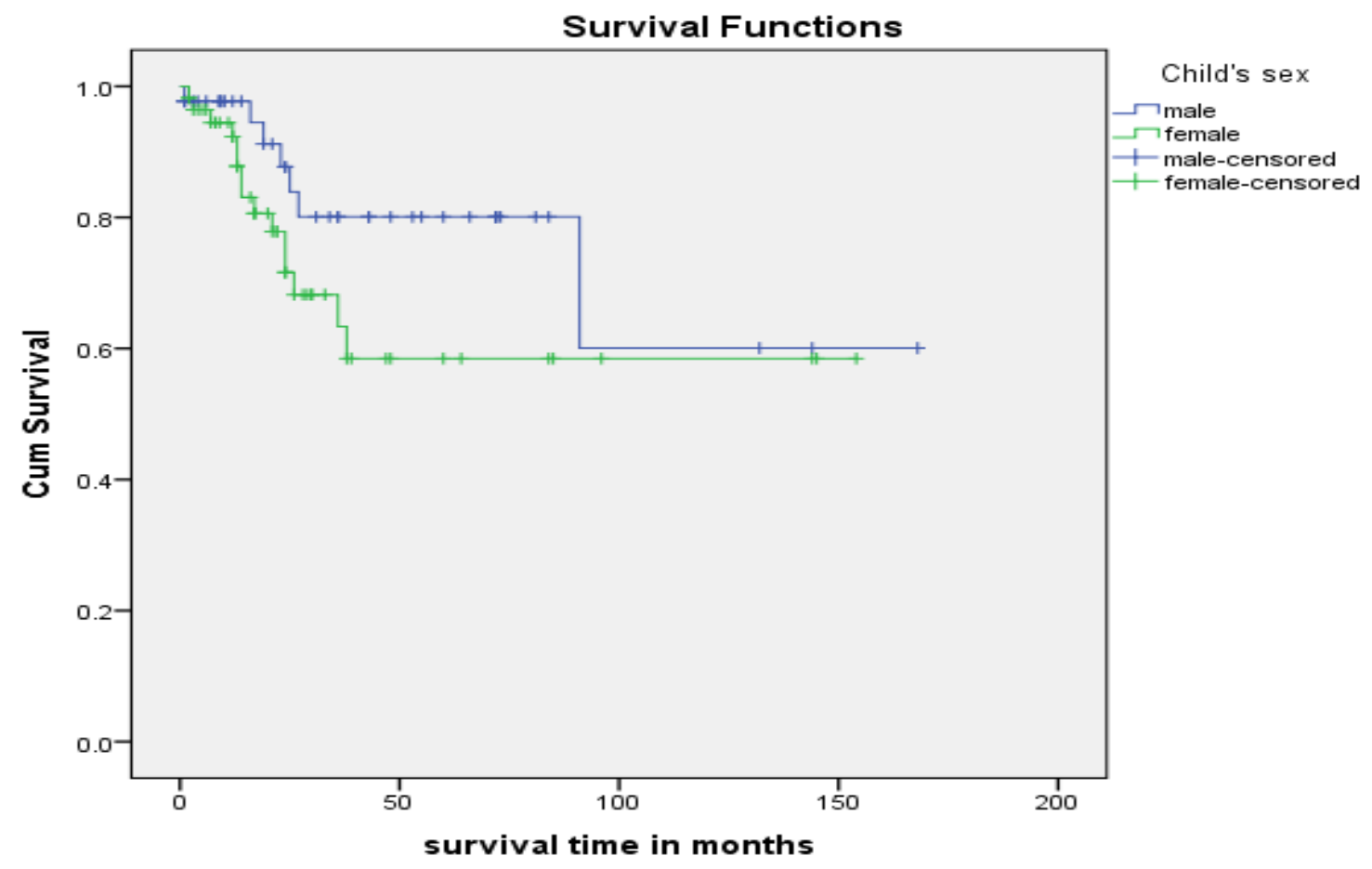

Figure 2: Kaplan meier survival curve by Gender difference,TASH 2017.

DOI: http://dx.doi.org/10.4314/ejhs.v29i2.3 
Pulmonary hypertension was diagnosed in 46 of the cases. Other associated anomalies including hypothyroidism and gastrointestinal disorders were diagnosed in 21 and 4 of the cases, respectively. Maternal age (mean and median) at conception were 32 years, with the range between 21 and 43 years. Sixty-nine percent of the mothers were under the age of 35 years at the time of conception.

\section{DISCUSSION}

The detection rate at or before one year of age for cardiac anomalies in the current study was $61 \%$. This was comparable result with a similar study in England, which is $82 \%$. According to reports, the age at which congenital cardiac anomaly is detected reflects the overall health facilities of a country (24). Most of the cases in the current study were diagnosed during infancy. In the first place, diagnosis was made only clinically using phenotypic features. Since blood and ultrasound test were not available in Ethiopia for antenatal diagnosis of DS, none of the cases had confirmed diagnosis. Although the testes are done routinely on pregnant mothers in countries with well developed facilities, for communities like ours, it is recommended to use careful clinical assessment of suspected cases at birth (25) (22).

The sex ratio of cases in the current study showed female preponderance. Although the comparison is difficult for small sample size like this one, the finding is in contrary to reports from else where. For example,Verma RS et al showed male predominance in their report (26). On the other hand, Kovaleva et al in a review of articles showed a male preponderance while female dominance was seen in mosaics $46 / 47,+21$ cases. No male preponderance was found among patients with DS not tested cytogenetically. They concluded that the female sex dominance that occurred may be a false-positive result (27). This observation may explain our finding in this study since none of our cases were diagnosed cytogenetically. Future practice should aim to do karyotyping for all suspected cases whenever possible. Likewise, higher number of females were found to have atrio-ventricular septal defect in the current study. Others also demonstrated the same findings (28).

PDA is the commonest cardiac anomaly observed in the current study. In like manner, A similar finding was reported from Guatemala (14). Infact, both studies were institutional. On the other hand, in a population based study, from the developed countries, AVSD were reported as the commonest cardiac lesion among Down patients (29).

Increased prevalence of PDA and ASD is reported with higher altitude (30). Because majority of our cases came from an area where the altitude is above 2300 meters above sea level, our finding may have some thing to do with this altitude difference. The mechanism of increased PDA at high altitude is presumed to be a mechanical factor affecting the pulmonary circulation and the lower oxygen tension that influence persistence of the ductus at high altitude (31).

From literature point of view, we observed four different patterns of cardiac lesions in DS. As we discussed earlier, in the reports from Guatamala and Nigeria, PDA was predominantly reported $(18,28)$ while VSDs were reported more frequently in India, China, and Saudi Arabia (5). It should be noted that most of these studies are institution based. On the other hand, AVSD is the most common cardiovascular anomaly observed in Italy and USA(12,29). The fourth pattern of occurrence is reported from Mexico and Libya showing high proportion of ASD (32-34). Weather the observed differences are due to design effect or true ethnic difference needs to be worked out. Diogenes et al attributed such a difference to the inherent characteristics of the studied population (28).

We observed high death and lost to follow-up rate in the current study, and most $\left(2 / 3^{\text {rd }}\right)$ of them occurred during infancy. Those deaths may be due to the frequent heart failure and/or infections. It is notably reported that congenital heart disease and pneumonia caused frequent death in DS babies, especially in early childhood (35).

Pulmonary hypertension $(\mathrm{PH})$ is observed in $40 \%$ of the cases in the current study. Interestingly, patients with DS develop pulmonary

DOI: http://dx.doi.org/10.4314/ejhs.v29i2.3 
hypertension precociously leading to progressive right ventricular dysfunction that may kill the patient (36). The increased incidence of $\mathrm{PH}$ is believed to be a result of additional problems, such as upper airway obstruction, pulmonary hypoplasia, structural lung disease, thinner media of the pulmonary arterioles, abnormal pulmonary vascular growth, alveolar hypoventilation, and recurrent pulmonary infection or gastroesophageal reflux (37).

Ethnic, socioeconomic or geographic differences may also be responsible for differences in mortality (38). According to reports from low income countries, the risks of mortality during infancy is double in DS cases compared to nonDS cases $(2,35)$. Most deaths occurred commonly among girls in the current study (Figures 1 and 2). The reason is not clear except that we know congenital cardiac anomaly occur more commonly in the female sex particularly AVSD, and the main cause of death is $\mathrm{CHD}(28)$. Esteban $\mathrm{E}$, et al reported that girls died from a broader range of causes compared to boys (40). At the same time, Rankin reported that infant's gender did not influence survival in DS (39). Further research is required with larger sample size to verify these contradicting observations.

In many developed countries, survival of cases increased markedly compared to the previous decades $(41,42)$. According to reports, survival was increased from $77.5 \%$ in $1985-1990$ to a predicted $90.7 \%$ in 1997-2003(39). As a matter of fact, people with DS typically live to about 55 years or longer in the US(43). Unfortunately, survival comparison with developing countries was not possible for lack of data in adult cases. About $41 \%$ reduction in infant death was reported by CDC (44). On the other hand, evidences on the factors affecting survival indicated that black maternal race, low birth weight, preterm birth, lower paternal education, presence of heart defects, and presence of other major congenital anomalies were important prognostic factors (45). Unfortunately, the above problems are common in low income countries including Ethiopia.

In the current study, nearly two-third of the mothers were under the age of 35 years. This is contrary to previous reports where older mothers are at risk for having affected child (46). Be that as it may, it was suggested that affected children are born to women under the age of 35 years with higher fertility rates than in women above the age of 35 years with less fertility, a feature commonly seen in developing countries $(47,48)$.

An important limitation in the current study is the small number of cases compared to the required sample size which the result may affect the confidence on which the conclusion is made. Future study with large sample size is recommended in order to verify our finding.

The authors would also like to acknowledge problems related to the operational definition of phenotype features in this study, as DS like features can occur in some cytogenetically normal babies. Few studies done on the accuracy of clinical diagnosis showed that clinical diagnosis of DS is inaccurate in one-third of cases (17). On the other hand, studies showed that $90 \%, 100 \%$ and $37.5 \%$ of trisomy, translocation and mosaic DS, were diagnosed on the basis of clinical features, respectively (22). Therefore, our report should be interpreted in the light of this fact. We also like to acknowledge pulmonary hypertension is diagnosed clinically and by echocardiography only while it should be confirmed by cardiac catheterization. Moreover, specific causes of death was not reported and factors affecting survival in affected children like birth weight were not retrieved. Future study on the topic should address the limitations discussed in this study.

In conclusion, patent ductus arteriosus is the commonest congenital cardiac anomaly in children born with Down syndrome at our institution. Effort has to be made to do Karyotyping in all suspected cases. Children born with Down syndrome should be evaluated early for presence of cardiovascular anomaly and referred earlier.

\section{ACKNOWLEDGEMENT}

The authors would like to thank the staff of the Department of Pediatrics and Child Health at TASH. We also would like to thank those who helped with reviewing the manuscript.

\section{REFERENCES}

DOI: http://dx.doi.org/10.4314/ejhs.v29i2.3 
1. Morris JK AE. Trends in Down's syndrome live births and antenatal diagnoses in England and Wales from 1989 to 2008: analysis of data from the National Down Syndrome Cytogenetic Register. BMJ 2009; 339: 3794.

2. Bell R RJ, Donaldson LJ. Northern congenital abnormality survey Steering Group. Pediatr Perinat Epidemiol, 2003 17(1):33-9.

3. Weijerman ME DWJ. Clinical practice.The care of children with Down syndrome. Eur J Pediatr. 2010;169:1445-52.

4. Glasson EJ SS, Hussain R, Petterson BA, Montgomery PD, Bittles AH.The changing survival profile of people with Down's syndrome: implications for genetic counselling.Clin Genet 2002; 62:390-3.

5. Inayatullah Khan TM. Frequency and Pattern of Congenital Heart Defects in Children with Down's syndrome in Lady Reading Hospital, Peshawar, Pakistan.Gomal Journal of Medical Sciences 2012;10 (2):241-3.

6. Stolf N. Congenital heart surgery in a developing country: a few men for a great challenge.Circulation.2007 116:1874-5.

7. Mulcahy MT. Determinants of early mortality in children born with Down syndrome.Clin Genet 1979; 16 (2):103-8.

8. Dennis J AN, Ellis J, Marder L. Recognizing heart disease in children with Down syndrome. Arch Dis Child EducPract Ed 2010; 95 98-104.

9. Amark K SJ. The effect of changing attitudes to Down's syndrome in the management of complete atrioventricularseptal defects.Arch Dis Child EducPract Ed. 1999; 81: 151-4.

10. Leonard S ea. Survival of infants born with DS. Pediatr perinat Epidemiol. 2000:198096

11. Summar K LB. Down Syndrome and Other Abnormalities of Chromosome Number. Philadelphia, USA: WB Saunders 2011.5 p.

12. Freeman SB TL, Dooley KJ, Alran K, Sherman SL, Hassold TJ, et al. Population based study of congenital heart defect in
Down syndrome. Am J Med Genet. 1998;80:213-7.

13. Kim MA LY, Yee NH, Choi JS, Choi JY, Seo K. . Prevalence of Congenital Heart Defects associated with Down syndrome in Korea. J Korean Med Sci 2014; 29:1544-9.

14. 14. Vida VL BJ, Larrazabal LA, Gaitan G, de Maria Garcia F, Castañeda AR. Congenital cardiac disease in children with Down's syndrome in Guatemala.Cardiol Young 2005;15(3):286-90.

15. K AS. Cardiac abnormalities of Sudanese patients with Down syndrome and their short term outcome. Cardiovasc $J$ Afr. 2009;20:112-5.

16. Z ELMAGRPY AR, A SHAH, E HABAS, EH ABURAWI. Down syndrome and CHD:Why the regional difference as observed in the lesbian experience.CVJAFRICA. 2011;22(6):1-4.

17. S Sivakumar SL. Accuracy of clinical diagnosis in Down's syndrome. Arch Dis Child EducPract Ed. 2004;89(691693.):691-3.

18. K. F. A score based on eight signs in the diagnosis of Down syndrome in the newborn.J ment Defic Res 1980;24(3):18-5.

19. Molla Taye MA, Wondowossen Fantaye, Ermias Diro, Alemayehu Worku. Magnitudes of birth defect in Central and Northwest Ethiopia from 2010-2014. A descriptive Retrospective Study. PLOS one. 2016;11(10):1-12.

DOI:10.1371/journal.pone.0161998

20. Science PEco. Sample Size Computation for Population Proportion Confidence Interval Penicilvannia, USA: Published on STAT 500; 2018. Available from: https://onlinecourses.science.psu.edu/stat50 0/node/31.

21. Wikipedia.congenital heart anomaly 2018. Available from: https://en.wikipedia.org/wiki/Congenital_he art_defect.

22. Morrison. LDaPJ. Accuracy of the clinical diagnosis of Down syndrome. Ulster Med $J$ 2004;73(1): 4-12.

DOI: http://dx.doi.org/10.4314/ejhs.v29i2.3 
23. Luthra A. Echo made Easy. Second edition ed. India: Jaypee Brothers Medical Publishers(p)LTD. NewDelhi; 2007. 4 p.

24. Bashir Ahmad bhat SAM, Anwar khan, Mohammad Ahmad Imam.PATTERN OF CONGENITAL HEART DISEASEAMONG CHILDREN IN MADINA MUNA W ARA.Journal of the Saudi Heart Association 1997;9(1).

25. Gynecologists ACoOa. Down syndrome Arizona: Myo foundation for medical education and Research; 2018 [cited 2018]. Available from: http://mayoclinic.org.

26. Verma RS HA.Sex ratio of children with trisomy 21 or Down syndrome.Cytobios 1987;51(20-207):145-8.

27. Kovaleva NV. Sex ratio in Down syndrome.Tsitol Genet. 2002;36(6):54-69.

28. Tereza Cristina Pinheiro, Diogenes FA, Jose Luiz de Lima Filho, Sandra da Silva Mattos.Gender difference in the prevalence of congenital heart disease in Down syndrome: a brief meta-analysis. $B M C$ Medical Genetics 2017 18: 111.

29. Sallie B. Freeman LFT, Kenneth J. Dooley, Katherine Allran, et al. Population- Based Study of Congenital Heart Defects in Down Syndrome. Am J Med Genet 1998; 80: 2137. 1998; 80: 213-7.

30. Miao CY ZJ, Zuberbuhler JR. Prevalence of congenital cardiac anomalies at high altitude. J Am CollCardiol. 1988; 12(1):224-8.

31. Bialkowiski J GJ, Zabal C, Garcia-Montes A, et al. Patent ductusarteriosus at low and high altitudes: anatomical and haemodynamic features and their implications for transcatheter closure. Kardiol Pol. 2011;69(5):431-6.

32. Lo NS LP, Lau KC, Yeung CY.Congenital cardiovascular malformation in Chinese children with Down syndrome. Chin Med J(Engl). 1989;102:382-6.

33. Kava MP TM, Muranjan MN, Girisha KM. Down syndrome, clinical profile from India. Arch Med Res. 2004;35:31-5.

34. FL A. Congenital heart disease and other major anomalies in patients with Down syndrome. Saudi Med J 2006;27:219-22.
35. David s. Newberger.State University of New York at Buffalo, Buffalo, New York. Down Syndrome: Prenatal Risk Assessment and Diagnosis. . AmFam Physician 2000 62(4):825-32.

36. Fukushima H KK, Sato R, Yagihashi T, et al. Mechanism of underlying early development of pulmonary vascular obstructive disease in Down syndrome:An imbalance in biosynthesis of thromboxane A2 and prostacyclin. Am J Med genet. 2010;152(A)(8):1919-24.

37. Al-Biltagi MA. Echocardiography in children with Down syndrome.World journal of clinical Pediatr 2013. 2013;2(4):36-45.

38. Hunter JE AE, Shin M, Bean LJ, et al. The association of low socioeconomic status and the risk of having a child with Down syndrome: a report from the National Down syndrome project.Genet Med 2013. 2013;15(9):698-705.

39. Judith Rankin PWGT, Mary Bythell, Mark S. Pearce. Predictors of Survival in Children Born With Down Syndrome: A RegistryBased Study. Pediatrics2012; 129 ( 6):.

40. Esteban E BE, Esparza M, Jordan I, Esteban ME. Sex difference in children with severe health conditions:Cause of admission, and mortality in a pediatric intensive Care unit.AM J Hum Biol 2015; 27(5):6139.

41. James E. Kucik, CsabaSiffel, Lisa Marengo, Adolfo Correa. Trends in Survival Among Children With Down Syndrome in 10 Regions of the United States. PEDIATRICS 2013;131(1): e27 -36.

42. Glasson.AHBCBRHEJ.The four ages of Down syndrome.European Journal of Public Health, . 2007; Volume 17(2):221 5.

43. Healthgrades R. Deaths from Down Syndrome: Survival rate statistics for Down Syndrome 2015. Available from: http://www.rightdiagnosis.com/d/down_synd rome/deaths.htm.

44. Down syndrome in the united states [Internet]. Available from: https://www.cdc.gov/ncbddd/birthdefects/do 
wnsyndrome/data.html.Downloaded August 2018.

45. Sonja A.Rasmussen L-YMAD, J.M.Friedman.Survival in infants with Down syndrome, Metropolitan Atlanta, 1979-1998.The Journal of Pediatrics. 2006;148,(6):806-12.e1

46. Emily Graves Allen caSBF, Charlotte Druschel, Charlotte A. Hobbs.Maternal age and risk for trisomy 21 assessed by the origin of chromosome non-disjunction: A report from the Atlanta and national Down syndrome projects. Hum Gent 2009;125(1):41-52. PubMed Central PMCID: PMC2833410.

47. Olsen CL CP, Gensburg LJ, Hughes JP.The effects of prenatal diagnosis, population ageing, and changing fertility rates on the live birth prevalence of Down syndrome in New York State, Prenat Diagn. 1996 16(11):991-1002.

48. Association. AP. Down Syndrome: Causes, Symptoms And Risks. 2015. Available from: American Pregnancy Association. http://americanpregnancy.org/birthdefects/down-syndromel 